\title{
PRODUCT PLACEMENT EFFECTIVENESS: A STUDY ON THE INTERNET
}

\author{
Su-Houn Liu, Chung Yuan Christian University, vandy@im.cycu.edu.tw \\ Hsiu-Li Liao, Chung Yuan Christian University, hsiuliliao@cycu.edu.tw \\ Hui-Ju Chen, Yuan Christian University, amychen@im.cycu.edu.tw
}

\begin{abstract}
Despite the burgeoning popularity of product placement as a marketing tool on the Internet, there is limited substantive empirical evidence regarding whether and how it is effective in impacting consumer responses. In this study, we try to answer the following two critical questions on conducting product placement marketing on the internet: First, in order to get the best result, should we choose the vehicle that its attribute is a match with the product that we intended to market. And, second, is the brand awareness of the vehicle has an impact on the effectiveness of the product placement marketing on the internet. Our findings indicated that: advertising through product placements on the internet can have the best result when the product attribute is match with the vehicle attribute. However, in order to get the best result, the internet marketers should choose the vehicle with higher customer awareness. We believe that this further highlights the importance of "integrating" your product placement advertising on the internet with the context and the vehicle.
\end{abstract}

Keywords: Internet Advertising, Product Placement and Social Media

\section{INTRODUCTION}

Product placement is the purposeful incorporation of commercial content into noncommercial settings, that is, a product plug generated via the fusion of advertising and entertainment [6]. Based on this definition, those social media platform such as facebook, twitter and blogs has become an ideal carrier for doing product placement on the internet. It didn't take long for marketers to eye the Internet as well. By the mid-2000s there were more than 100 million blogs on the Web and the company PayPerPost.com, founded by Ted Murphy, offered to pay bloggers to write reviews. A product placement advertising work much like the traditional "Advertorials," or paid ads that look like written opinions, have been around since the 1940s. Such shenanigans started in newspapers and you hear them still today on radio talk shows. "I'm Writing Late. Need Starbucks." By inserting a brand (such as Starbucks) promotion directly into a blog post, a blogger is giving the recipient no choice but to receive the message. While traditional media is dying; newspaper circulation is down and 1 in 4 U.S. homes has a DVR that lets consumers skip commercials, product placement has provided the advertisers a promising new ways to intercept people. Even though sometimes it's controversial, product placements on the internet can be a cost-effective method for reaching target customers. Because of this, product placements are likely to eclipse traditional advertising messages. Some marketers even believed that the product placement on the internet has just solved the monetization challenge of social media and prevented the global ad industry from imploding.

Despite the burgeoning popularity of product placement as a marketing tool on the Internet, there is limited substantive empirical evidence regarding whether and how it is effective in impacting consumer responses. In this study, we try to answer the following two critical questions on conducting product placement marketing on the internet: First, in order to get the best result, should we choose the vehicle that its attribute is a match with the product that we intended to market. And, second, is the brand awareness of the vehicle has an impact on the effectiveness of the product placement marketing on the internet. Based on the findings of previous studies, we have proposed that these factors interact to influence the effectiveness of the product placement conducts.

\section{LITERATURE REVIEW}

In terms of the Internet, consumers want to communicate with their related others so that they can get the information they need and trust. So, companies need to listen to online conversations and establish what interests 


\section{Issues in Information Systems}

Volume 13, Issue 2, pp. 253-259, 2012

their online community. Then, they can provide that information in an engaging format including storytelling, articles, images, and video [5]. Liao, Liu, Pi and Chen [10] have tested their hypothesis and their findings indicate that the effects of product placement conducts on the Internet are similar to the effect of product placement in other media.

In the effort to enhance the effectiveness of product placement, there is an old paradox known to marketers: "If you notice it, it's bad. But if you don't notice, it's worthless" [4]. In its simplest form, product placement on the internet consists of an advertiser or company producing some engaging content in order to sell their product. The content will be integrated into a vehicle (either a message or an article or even an online game) provided by the internet media (for example, a blog run be a famous blogger). The target customers or the audiences, by reading or watching the vehicle, will notice the content. And through the linkage (usually a hyperlink) between the content and the vehicle, the customers will be lead to the target site for more marketing information.

Vehicles play an important role on the effectiveness of the product placement marketing [3]. The advent of mediasharing sites, especially along with the so called Web 2.0 wave, has led to unprecedented delivery channel of market placement advertising. Industry and various academic studies have acknowledged the importance of the awareness and reliability of the customer to the vehicle [1,9]. It is valuable for the product placement marketer to know the difference in effectiveness when considering integrating their advertising with various types of vehicles. Therefore, our two research question is: First, will it generated a better result when we choose a vehicle that its attribute is a match with the product that we intended to market. And, second, when we place the message on the vehicle with higher customer awareness, will it increase the effectiveness of the product placement marketing on the internet.

The research hypotheses to be tested are as follows:

$\mathrm{H}_{1}$ : Product attributes that match with the vehicle attributes will raise the advertising effectiveness.

$\mathrm{H}_{1 \mathrm{a}}$ : Product attributes that match with the vehicle attributes can make higher click rate.

$\mathrm{H}_{1 \mathrm{~b}}$ : Product attributes that match with the vehicle attributes can make deeper browse depth on the product website.

$\mathrm{H}_{1 \mathrm{c}}$ : Product attributes that match with the vehicle attributes can make longer browsing time on the product website.

$\mathrm{H}_{2}$ : Product presented on different brand awareness vehicle will significantly affects the advertising effectiveness.

$\mathrm{H}_{2 \mathrm{a}}$ : Product presented on high brand awareness vehicle makes higher click rate.

$\mathrm{H}_{2 \mathrm{~b}}$ : Product presented on high brand awareness vehicle makes deeper browse depth of product website.

$\mathrm{H}_{2 \mathrm{c}}$ : Product presented on high brand awareness vehicle makes more browsing time of product website.

\section{The Research Model}

The research model empirically tested in this study is shown in Fig. 1. It represents the proposed research model drawn from the constructs of vehicle attributes, brand awareness, and advertising effectiveness. It is proposed in this model that different types of vehicle attributes and brand awareness are potential determinants of the advertising effectiveness as the independent variable for this study. 


\section{Issues in Information Systems}

Volume 13, Issue 2, pp. 253-259, 2012

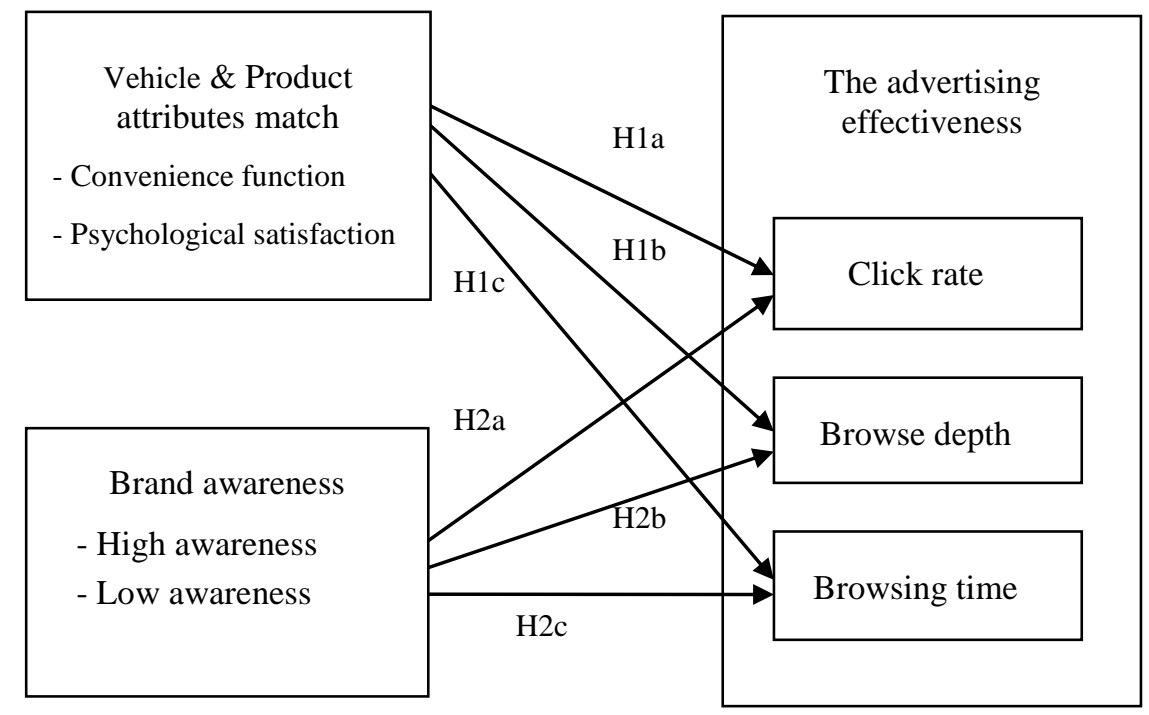

Figure 1. The Research Model

\section{RESEARCH METHODOLOGY}

This study used a field experiment to test the research hypotheses. This section describes the participants and procedures.

\section{Participants and Procedures}

The subjects were recruited from the SogiKing website (http://www.sogi.com.tw) during four days. The word "SoGi" mean cell phone in mandarin. The SogiKing website is one of the most popular community websites in Taiwan. People come to the website to share and browse articles about the cell phones. Random sampling was used to assign users to read one of four types of the product report about mobile phone. In the production report about mobile phone, the functional bag product also was displayed. The users who were interested in the functional bag product can click the hyperlink of the bag product website. The numbers of group subjects browse the bag product websites are showed in Table 1.

The articles on the SogiKing are the vehicle for our product placement marketing. There are two major type for those articles that introduce a new cell phone: convenience function and psychological satisfaction. Articles with convenience function attribute (Figure 2) emphasize on the function of the cell phone. On the other hand, articles with psychological satisfaction attribute (Figure 3) emphasize on the psychological satisfaction of using the cell phone. The product that we want to promote is an ambi bag (Figure 4) from Promax Company. The bag has a marketing strategy that emphasize on its convenience function. So when we place the product on an article that has a convenience function attribute, that is a match between the product and vehicle. When it was place on an article that has a psychological satisfaction attribute, it is a un-match between the product and vehicle.

Brand awareness was operated to divide into high awareness and low awareness group. According to the experts' suggestion and product availability, the study selected articles that introduce a cell phone from Sony Ericsson as the high awareness group and articles that introduce another cell phone from Utec as the low awareness group to test the experiment. Therefore, the study conducted $2 \mathrm{X} 2$ experiment to examine the model and hypotheses. 


\section{Issues in Information Systems}

Volume 13, Issue 2, pp. 253-259, 2012

Table 1. Four groups in the experiment

\begin{tabular}{|c|c|c|c|}
\hline Vehicle attributes & Brand awareness & \multicolumn{2}{|c|}{ Responses } \\
\hline \multirow{2}{*}{$\begin{array}{c}\text { Convenience function } \\
\text { attribute }\end{array}$} & High & 58 & \multirow{2}{*}{117} \\
\cline { 2 - 3 } & Low & 59 & \multirow{2}{*}{102} \\
\hline $\begin{array}{c}\text { Psychological satisfaction } \\
\text { attribute }\end{array}$ & High & 45 & 57 \\
\cline { 2 - 3 }
\end{tabular}

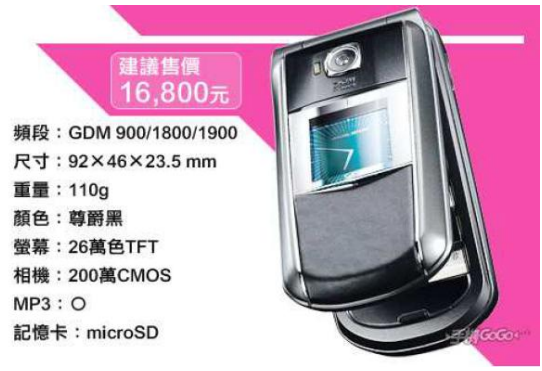

Figure 2: convenience function attribute

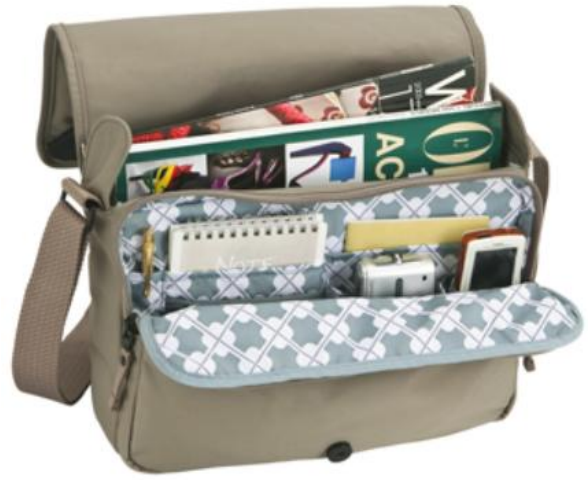

Figure 4: Promax ambi bag

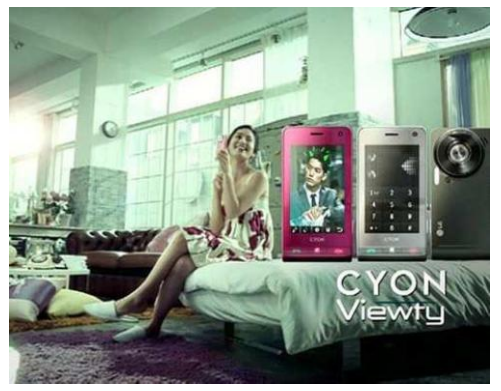

Figure 3: psychological satisfaction attribute

\section{RESULTS}

Click rate indicates the times which the subjects click the hyperlink of the bag product website divided by the times which the subjects click the product hyperlink on the vehicle. Browse depth pointed out the level of users' page views. Besides, browsing time demonstrated the time subjects visit the bag product website. The average click rate, browse depth and browsing time of each group are displayed in Table 2.

In Table 2, when vehicle attribute is convenience function, high brand awareness can make deeper browse depth of product website and longer browsing time than low brand awareness. When vehicle attribute is psychological 


\section{Issues in Information Systems}

Volume 13, Issue 2, pp. 253-259, 2012

satisfaction, high brand awareness can make high click rate, deeper browse depth and longer browsing time on product website than low brand awareness.

Table 2. The average click rate, browse depth and browsing time of each group

\begin{tabular}{|c|c|c|c|c|}
\hline \multirow{2}{*}{$\begin{array}{c}\text { Vehicle } \\
\text { attributes }\end{array}$} & \multirow{2}{*}{ Brand } & \multicolumn{3}{|c|}{ Advertising effectiveness } \\
\cline { 3 - 5 } & awareness & Click rate & Browse depth & Browsing time \\
\hline $\begin{array}{c}\text { Convenience } \\
\text { function } \\
\text { attribute } \\
\text { (match) }\end{array}$ & High & $8.42 \%$ & 5.67 & $0: 07: 03$ \\
\cline { 2 - 5 } & Low & $9.15 \%$ & 2.26 & $0: 04: 47$ \\
\hline $\begin{array}{c}\text { Psychological } \\
\text { satisfaction } \\
\text { attribute } \\
\text { (un-match) }\end{array}$ & High & $8.06 \%$ & 4.07 & $0: 04: 52$ \\
\cline { 3 - 5 } & Low & $6.22 \%$ & 1.46 & $0: 00: 46$ \\
\hline
\end{tabular}

Data associated with click rate, browse depth and browsing time was analyzed using a two-way ANOVA test with the independent variable in Table 3. Both the effects of vehicle attributes and brand awareness have some significant differences in browse depth and browsing time. However, vehicle attributes and brand awareness have no interactive impact on click rate, browse depth and browsing time.

Table 3. The impact of vehicle attributes and brand awareness on advertising effectiveness

\begin{tabular}{|c|l|c|c|}
\hline Independent variable & Dependent variable & $\mathbf{F}$ & P-value \\
\hline \multirow{3}{*}{ Vehicle attributes } & Click rate & 0.303 & 0.583 \\
\cline { 2 - 4 } & Browse depth & 5.761 & $0.018^{* *}$ \\
\cline { 2 - 4 } & Browsing time & 11.256 & $0.001^{* * *}$ \\
\hline \multirow{3}{*}{ Brand awareness } & Click rate & 0.012 & 0.912 \\
\cline { 2 - 4 } & Browse depth & 36.290 & $0.000^{* * *}$ \\
\cline { 2 - 4 } & Browsing time & 11.912 & $0.001^{* * *}$ \\
\hline \multirow{3}{*}{$\begin{array}{c}\text { Vehicle attributes } * \\
\text { Brand awareness }\end{array}$} & Click rate & 0.589 & 0.444 \\
\cline { 2 - 4 } & Browse depth & 0.647 & 0.423 \\
\cline { 2 - 4 } & Browsing time & 0.964 & 0.328 \\
\hline
\end{tabular}

The subjects read the report with vehicle attribute match with product attribute have deeper browse depth and more browsing time in Table 4. Hypotheses $\mathrm{H}_{1 \mathrm{~b}}$ and $\mathrm{H}_{1 \mathrm{c}}$ were supported by the data. The subjects who browse the product report with high brand awareness vehicle have deeper browse depth and more browsing time than low brand awareness in Table 5. Hypotheses $\mathrm{H}_{2 \mathrm{~b}}$ and $\mathrm{H}_{2 \mathrm{c}}$ were supported by the results. However, $\mathrm{H}_{1 \mathrm{a}}$ and $\mathrm{H}_{2 \mathrm{a}}$ were not supported. 


\section{Issues in Information Systems}

Volume 13, Issue 2, pp. 253-259, 2012

Table 4. Average difference in advertising effectiveness with different vehicle attributes

\begin{tabular}{|c|c|c|c|}
\hline Dependent variable & $\begin{array}{c}\text { Average difference } \\
(\mathbf{I}-\mathbf{J})\end{array}$ & Standard error & P-value \\
\hline Click rate & 0.005 & 0.008 & 0.583 \\
\hline Browse depth & 1.201 & 0.500 & $0.018^{* *}$ \\
\hline Browsing time & 185.739 & 55.386 & $0.001^{* * *}$ \\
\hline
\end{tabular}

I: Convenience function attribute

$\mathrm{J}$ : Psychological satisfaction attribute

$* * * \mathrm{p}<0.01, * * \mathrm{p}<0.05, * \mathrm{p}<0.1$

Table 5. Average difference in advertising effectiveness with different brand awareness

\begin{tabular}{|c|c|c|c|}
\hline Dependent variable & $\begin{array}{c}\text { Average difference } \\
\text { (I-J) }\end{array}$ & Standard error & P-value \\
\hline Click rate & -0.001 & 0.008 & 0.912 \\
\hline Browse depth & 3.014 & 0.500 & $0.000^{* * *}$ \\
\hline Browsing time & 191.080 & 55.363 & $0.001^{* * *}$ \\
\hline
\end{tabular}

I: High brand awareness

J: Low brand awareness

$* * * \mathrm{p}<0.01, * * \mathrm{p}<0.05, * \mathrm{p}<0.1$

\section{CONCLUSIONS}

Product placement on the internet has become an increasingly popular way of reaching potential customers who are able to zap past commercials. To reach these retreating audiences, internet marketers have to use product placements increasingly in more clever, effective ways that do not cost them too much.

In this study, three measurements were used to measure the effectiveness of the product placement marketing on the SogiKing website. They are the click rate, browse depth and browsing time on the product website.

There are two research questions in our research. In the first question, we try to find out that will it generated a better result when we choose a vehicle that its attribute is a match with the product that we intended to market. Our findings indicated that a match between the vehicle and product will have a deeper browse depth and loger browsing time on the product website, compare to the un-match group. But there are no significant difference between the match group and un-match group on the click rate.

For the second research question, we place the message on the vehicles with higher or lower customer awareness. Our findings indicated that product placement on higher awareness vehicle will have a better result. On browse depth and browsing time on the product website, the high awareness group outperforms the low awareness group. But there is no significant difference between two groups on the click rate. Our finding also indicated that vehicle attributes and brand awareness have no interactive impact on click rate, browse depth and browsing time.

Presently, advertising through product placements on the internet can have the best result when the product attitude is match with the vehicle attribute. However, in order to get the best result, the internet marketers should choose the vehicle with higher customer awareness. Our results provide further evidence that the impact of product placement 


\section{Issues in Information Systems}

Volume 13, Issue 2, pp. 253-259, 2012

is not a simple phenomenon, but rather that effects are qualified by many moderating factors. We believe that this further highlights the importance of "integrating" your advertising with the context and the vehicle, which is frequently noted by both academics and industry experts but ignored by many internet marketers.

\section{REFERENCES}

1. Aaker, D. A. (1991). Managing brand equity. New York, NY: The Free Press.

2. Brackett, L. K. and Carr, B. N. (2001). Cyberspace advertising vs. other media: Consumer vs. mature student attitude. Journal of Advertising Research, 23-32.

3. Broniarczyk, S. M. \& Alba, J. (1994) The Role of Consumers' Intuitions in Inference Making, Journal of Consumer Research, 21(3), 393-407.

4. Ephron, E. (2003). The Paradox of Product Placement. Mediaweek, 20.

5. Falkow, S. (2010). PR Trends 2010: Branded Content. The Proactive Report. Retrieved on November 14, 2010 from http://www.proactivereport.com/c/pr/pr-trends-2010-brandedcontent/.

6. Ginosar, A. \& Levi-Faur, D. (2010). Regulating Product Placement in the European Union and Canada: Explaining Regime Change and Diversity. Journal of Comparative Policy Analysis, 12(5), 467.

7. Gupta, P.B. \& Gould, S.J. (2007). Recall of Products Placed as Prizes Versus Commercials in Game Shows. Journal of Current Issues and Research in Advertising, 29(1), 43-53.

8. Gupta, P. B. and Lord, K. R. (1998). Product placement in movies: The effect of prominence and mode on recall. Journal of Current Issues and Research in Advertising, 20, 47-59.

9. Hoyer, W. D. \& Brown, S. P (1990) Effects of Brand Awareness on Choice for a Common, Repeat-Purchase Product. Journal of Consumer Research, 17(2), 141-148.

10. Liao, H. L.., Liu, S. H., Pi, S. M. and Chen, H. J.(2011). The Effect of Product Placement Marketing on Effectiveness of Internet Advertising, Communications in Computer and Information Science, 135, 332-337.

11. Homer, P. M. (2009). Product Placements: The Impact of Placement Type and Repetition on Attitude. Journal of Advertising, 38(3), 21-31.

12. Martin, B.A.S., Durme, J.V., Raulas, M., and Merisavo, M. (2003). Email Advertising: Exploratory Insights from Finland. Journal of Advertising Research, 43:3:293-300

13. Russell, C. A. (1998). Toward a framework of product placement: Theory propositions. Advances in Consumer Research, 25, 357-362.

14. Russell, C. A. (2002). Investigating the effectiveness of product placements in television shows: The role of modality and plot connection congruence on brand memory and attitude. Journal of Consumer Research, 29(3), 306-318. 